\title{
Nonlinear Seismic Behavior of Different Boundary Conditions of Transmission Line Systems under Earthquake Loading
}

\author{
Li Tian and Xia Gai \\ School of Civil Engineering, Shandong University, Jinan, Shandong 250061, China \\ Correspondence should be addressed to Li Tian; tianli@sdu.edu.cn
}

Received 9 June 2015; Revised 24 September 2015; Accepted 30 September 2015

Academic Editor: Mario Terzo

Copyright ( 2016 L. Tian and X. Gai. This is an open access article distributed under the Creative Commons Attribution License, which permits unrestricted use, distribution, and reproduction in any medium, provided the original work is properly cited.

\begin{abstract}
Nonlinear seismic behaviors of different boundary conditions of transmission line system under earthquake loading are investigated in this paper. The transmission lines are modeled by cable element accounting for the nonlinearity of the cable. For the suspension type, three towers and two span lines with spring model (Model 1) and three towers and four span lines' model (Model 2) are established, respectively. For the tension type, three towers and two span lines' model (Model 3) and three towers and four span lines' model (Model 4) are created, respectively. The frequencies of the transmission towers and transmission lines of the suspension type and tension type are calculated, respectively. The responses of the suspension type and tension type are investigated using nonlinear time history analysis method, respectively. The results show that the responses of the transmission tower and transmission line of the two models of the suspension type are slightly different. However, the responses of transmission tower and transmission line of the two models of the tension type are significantly different. Therefore, in order to obtain accurate results, a reasonable model should be considered. The results could provide a reference for the seismic analysis of the transmission tower-line system.
\end{abstract}

\section{Introduction}

Transmission line is an important facility and a continuous structure which is made up of transmission towers and transmission lines [1]. Its failure may lead to the outage of power supply [2]. However, there are no code provisions for seismic design of transmission tower-line coupled system [3, 4]. Owing to the interaction of adjacent towers, transmission tower-line system is a complex space towers and lines coupled system, so its accurate calculation is difficult and complex [5]. It is unrealistic to assume that the transmission tower-line system is safe to go through earthquakes without adequate analysis. When the transmission tower-line system is located in strong earthquake zone, the response of the structure under seismic loading may be larger than that of wind load and ice load. There are several recent cases of damage to transmission tower-line system during earthquakes. During the 1994 Northridge earthquakes, 85 cables were damaged when they fell off their towers and two transmission towers collapsed due to high earthquake [6]. In the 1999 CHI-CHI earthquake, transmission towers and lines were damaged most severely, and a lot of lines were broken and some towers collapsed [7, 8]. During the 2008 Wenchuan earthquake, Sichuan electric network was severely damaged [9]. Some transmission lines were ruptured during the 2013 Lushan earthquake. Therefore, seismic action may govern the design of transmission tower-line system in high-intensity earthquake zones.

Researchers have done some analysis on the response of transmission tower-line system under seismic excitation in the past decades. Li et al. [10, 11] have completed a number of studies on the seismic response of transmission towers and have verified that the effect of lines in seismic design should not be neglected. Suzuki et al. [12] applied the frequency response method as the seismic response analysis to investigate characteristics of towers concerned with overhead wires. Ghobarah et al. [13] investigated the effects of multisupport excitations on the response of overhead power transmission lines. Li et al. [14] presented the mechanical model of soilpile-structure interaction of transmission tower-cable system in in-plane and derived the corresponding equations of motion. Lei and Chien [15] studied the dynamic behavior 


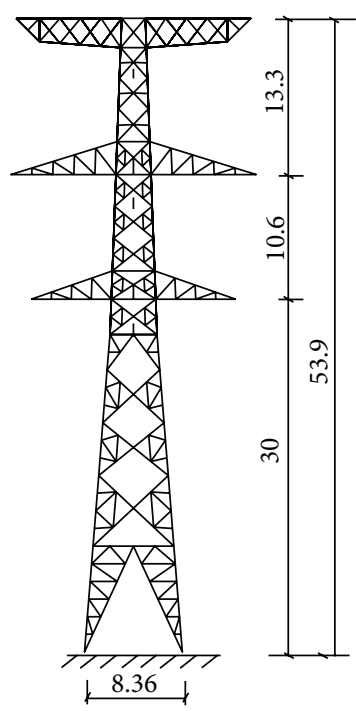

(a) Suspension type

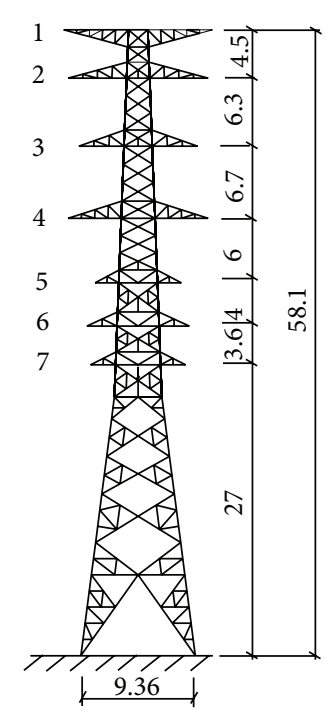

(b) Tension type

FIGURE 1: Transmission tower model (m).

of a group of transmission towers linked together through electrical wires and subjected to a strong ground motion. Bai et al. [16] investigated the response of a transmission tower-line system at a canyon site to spatially varying ground motions. The results showed that the effect of ground motion spatial variations should be incorporated in seismic analysis of the transmission tower-line system. Wang et al. [17] researched the progressive collapse analysis of a transmission tower-line system under earthquake. The results indicated that the proposed procedure can provide collapse mode and vulnerable points for use in seismic performance and retrofit evaluation of structure. Wu et al. [18] compared the seismic response of a large crossing transmission tower-line system subjected to near-fault pulse-like ground motions and ordinary ground motions. Tian et al. [19] analyzed the effects of boundary conditions, ground motion spatial variations, the incident angle of the seismic wave, coherency loss, and wave travel on the responses of the tension type of the transmission tower-line system, respectively. The comparisons of the longitudinal response of the two models are obtained only, but the comparisons of the transverse and vertical responses of the two models are not researched. Transmission tower-line system is different from general civil engineering structures. The most notable feature is that it contains complex mechanical properties of transmission lines, and the geometric nonlinearities of transmission lines are very significant. So the reasonable model of transmission tower-line system is very important. However, there are little studies about the boundary conditions of the transmission line system under seismic excitation. Not to mention the boundary conditions analysis of the system under multicomponent multisupport seismic excitations.

Nonlinear seismic behavior of different boundary conditions of transmission line systems under nonuniform seismic excitations is studied in this paper. The transmission towers are modeled by beam elements, while the transmission line is modeled by cable elements that account for the nonlinear geometry of the transmission lines. The frequencies of transmission towers and lines of the suspension type and tension type are calculated according to dynamic characteristic analysis, respectively. The responses of the suspension type and tension type of the transmission tower-line system under multicomponent and multisupport seismic excitations are performed using nonlinear time history analysis method, respectively. The results could provide a reference for seismic analysis of the transmission tower-line system.

\section{Structural Model}

Figure 1 shows the transmission tower models. Two different types of transmission towers are selected: (a) suspension type and (b) tension type. The height of the suspension type tower and tension type tower is $53.9 \mathrm{~m}$ and $58.1 \mathrm{~m}$, respectively. The structural members of the two types of towers are made of angle steel with the elastic modulus of $206 \mathrm{GPa}$. Based on real projects, three-dimensional finite element tower-line systems are established using SAP2000 software. The connections of members are rigid, and it has been approved that the numerical results of transmission tower using beam element are close to the test results [20], so the beam elements are selected for the simulation of the transmission towers.

To consider the effect of the other part of the transmission line, the boundary condition of the system should be simulated. To compare the responses with different boundary conditions, different models are established. Figure 2 shows the suspension type transmission tower-line system models. Three towers and two span lines with spring model (Model 1) and three towers and four span lines' model (Model 2) are established, respectively. The stiffness constants of the springs are defined by the adjacent transmission lines. The tension type transmission tower-line system models are shown in 


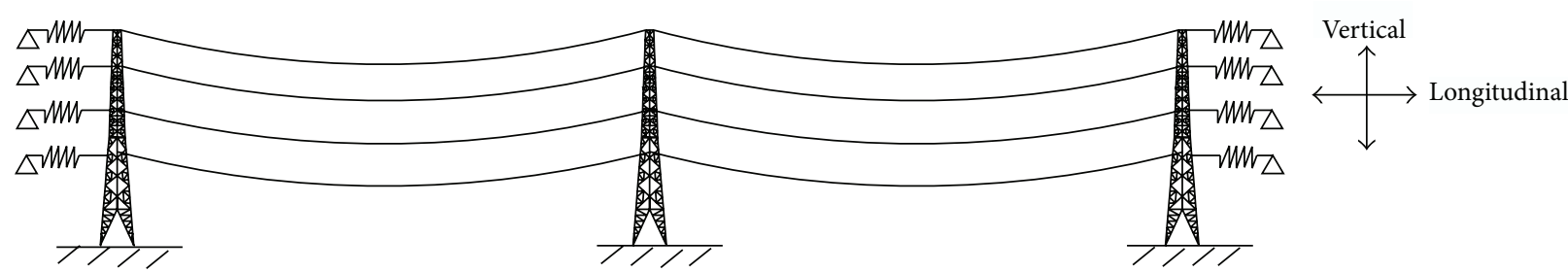

(a) Three towers and two span lines with spring model

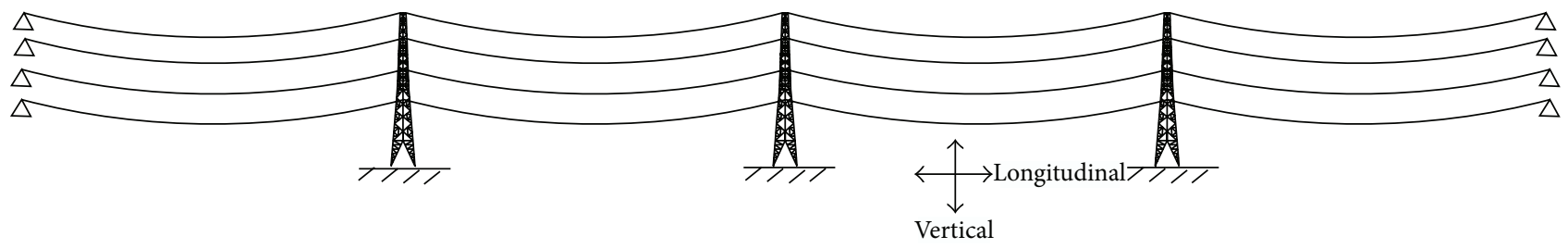

(b) Three towers and four span lines' model

FIGURE 2: Suspension type transmission tower-line system models.

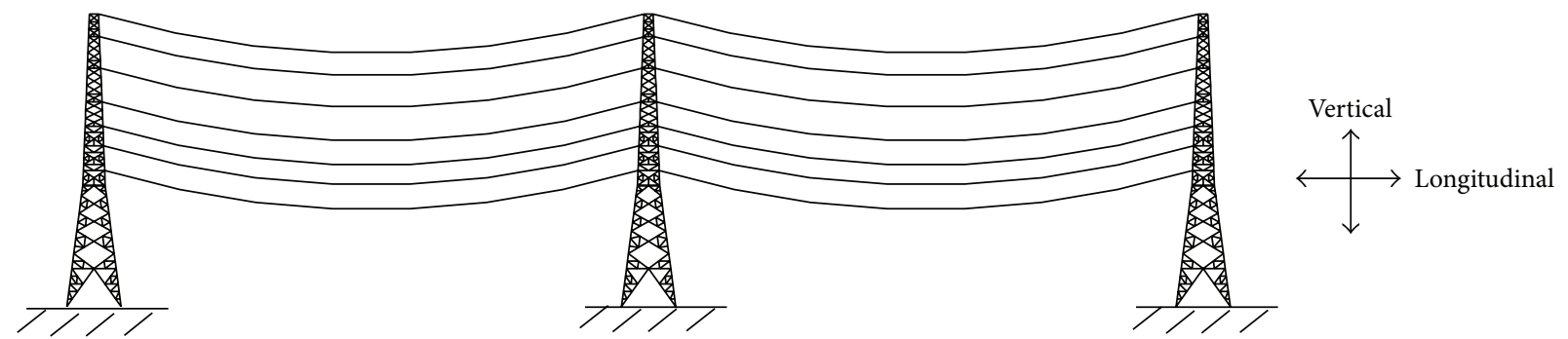

(a) Three towers and two span lines' model

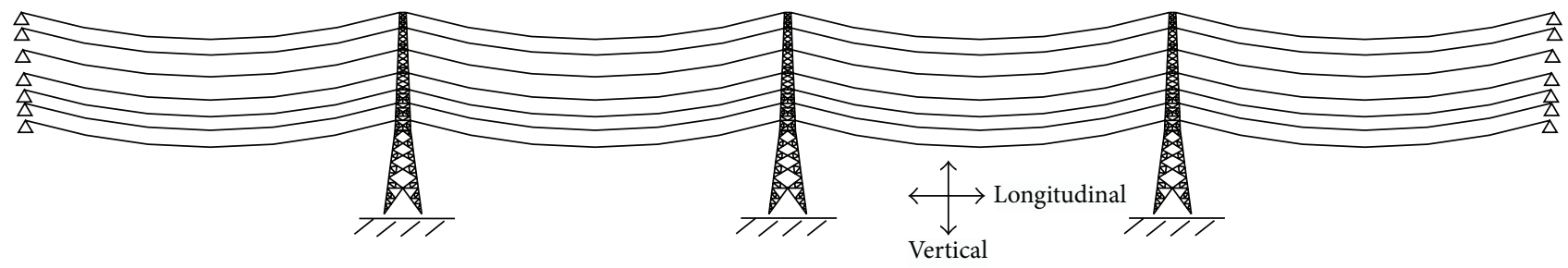

(b) Three towers and four span lines' model

FIgURE 3: Tension type transmission tower-line system models.

Figure 3. Three towers and two span lines' model (Model 3) and three towers and four span lines' model (Model 4) are created, respectively.

For the suspension type transmission tower, the types of ground line and conductor are LGJ-95/55 and LGJ-400/35, respectively. The ground line and conductor properties of the suspension type are shown in Table 1 . The upper two cables of every span are ground lines and lower six cables of every span are four bundled conductors. For the tension type transmission tower, the types of ground line and conductor are JLB40-150, LGJ-400/35, and LGJ-240/30, respectively. Ground line and conductor properties of tension type are listed in Table 2. The upper two cables of every span are ground lines and lower twelve cables of every span are two bundled conductors.
TABLE 1: Ground line and conductor properties of the suspension type.

\begin{tabular}{lcc}
\hline Type & $\begin{array}{c}\text { Ground line } \\
\text { LGJ-95/55 }\end{array}$ & $\begin{array}{c}\text { Conductor } \\
\text { LGJ-400/35 }\end{array}$ \\
\hline Outside diameter $(\mathrm{m})$ & $16.00 E-3$ & $26.82 E-3$ \\
Area $\left(\mathrm{m}^{2}\right)$ & $152.81 E-6$ & $425.2 E-6$ \\
Young's modulus $(\mathrm{MPa})$ & 105000 & 65000 \\
Poisson's ratio & 0.3 & 0.3 \\
Density $\left(\mathrm{Kg} / \mathrm{m}^{3}\right)$ & 4559.3 & 3172.3 \\
\hline
\end{tabular}

The spans to adjacent towers of suspension and tension types are all $400 \mathrm{~m}$. The base points of the transmission tower are fixed to the ground. The connections between 
TABLE 2: Ground line and conductor properties of the tension type.

\begin{tabular}{lccc}
\hline \multirow{2}{*}{ Type } & Ground line & \multicolumn{2}{c}{ Conductor } \\
& JLB40-150 & LGJ-400/35 & LGJ-240/30 \\
\hline Outside diameter $(\mathrm{m})$ & $15.75 E-3$ & $26.82 E-3$ & $21.60 E-3$ \\
Area $\left(\mathrm{m}^{2}\right)$ & $148.0 E-6$ & $425.2 E-6$ & $275.9 E-6$ \\
Young's modulus (MPa) & 103600 & 65000 & 73000 \\
Poisson's ratio & 0.3 & 0.3 & 0.3 \\
Density $\left(\mathrm{Kg} / \mathrm{m}^{3}\right)$ & 4705.2 & 3172.3 & 3341.7 \\
\hline
\end{tabular}

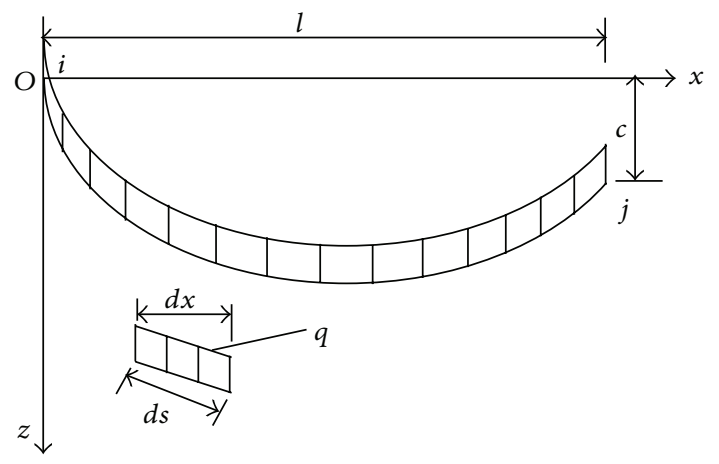

Figure 4: Coordinates of a single cable under self-weight.

transmission towers and lines of the suspension type and tension type are hinged by suspension and tension insulators, respectively. The bar element is used to simulate insulator.

The initial axial force and large deformation effect of cable are taken into consideration. Under self-weight, the cable spatial configuration is a catenary. Based on the coordinate system illustrated in Figure 4, the mathematical expression used to define the initial geometry of the cable profile is given in the following form [21]:

$$
z=\frac{H}{q}|\cosh (\alpha)-\cosh | \frac{2 \beta x}{l}-\alpha||
$$

where $\alpha=\sinh ^{-1}|\beta(c / l) / \sin (\beta)|+\beta, \beta=q l / 2 H$, in which $H$ represents initial horizontal tension which can be obtained from a preliminary static analysis and $q$ denotes uniformly distributed gravity loads along the transmission line.

\section{The Selection of Seismic Wave and Analytical Method}

3.1. The Selection of Seismic Wave. El Centro wave (May 19, 1940 ) is selected in this paper. The seismic waves include two horizontal components and one vertical component. The NS, $\mathrm{WE}$, and vertical components of the seismic wave coincide with the longitudinal, transverse, and vertical directions of the transmission tower-line system, respectively. The peak ground acceleration is adjusted to $0.4 \mathrm{~g}$, and the increases of the peak accelerations of the other two directions of seismic wave are equal proportions. Longitudinally extended structure such as transmission tower-line system is often multisupported, and the effect of wave travel is considered with apparent velocity $1000 \mathrm{~m} / \mathrm{s}$.
3.2. Analytical Method. n-degree-of-freedom linear system subjected to $m$ support motions can be written in the matrix form $[22,23]$ :

$$
\begin{gathered}
{\left[\begin{array}{ll}
\mathbf{M}_{a a} & \mathbf{M}_{a b} \\
\mathbf{M}_{b a} & \mathbf{M}_{b b}
\end{array}\right]\left\{\begin{array}{c}
\ddot{\mathbf{x}}_{a} \\
\ddot{\mathbf{x}}_{b}
\end{array}\right\}+\left[\begin{array}{ll}
\mathbf{C}_{a a} & \mathbf{C}_{a b} \\
\mathbf{C}_{b a} & \mathbf{C}_{b b}
\end{array}\right]\left\{\begin{array}{c}
\dot{\mathbf{x}}_{a} \\
\dot{\mathbf{x}}_{b}
\end{array}\right\}} \\
+\left[\begin{array}{ll}
\mathbf{K}_{a a} & \mathbf{K}_{a b} \\
\mathbf{K}_{b a} & \mathbf{K}_{b b}
\end{array}\right]\left\{\begin{array}{l}
\mathbf{x}_{a} \\
\mathbf{x}_{b}
\end{array}\right\}=\left\{\begin{array}{c}
0 \\
\mathbf{P}_{b}(\mathbf{t})
\end{array}\right\},
\end{gathered}
$$

where $\mathbf{x}_{a}=\left[\mathbf{x}_{a 1}, \ldots, \mathbf{x}_{a n}\right]^{\mathrm{T}}$ is the $n$-vector of displacements at the unconstrained degrees of freedom. $\mathbf{x}_{b}=\left[\mathbf{x}_{b 1}, \ldots, \mathbf{x}_{b m}\right]^{\mathrm{T}}$ is the $m$-vector of prescribed support displacements. $\mathbf{M}_{a a}$, $\mathbf{C}_{a a}$, and $\mathbf{K}_{a a}$ are the $n \times n$ mass, damping, and stiffness matrices associated with the unconstrained degrees of freedom, respectively. $\mathbf{M}_{b b}, \mathbf{C}_{b b}$, and $\mathbf{K}_{b b}$ are the $m \times m$ matrices associated with the supported degrees of freedom. $\mathbf{M}_{\mathrm{ab}}, \mathbf{C}_{a b}$, and $\mathbf{K}_{a b}$ are the $n \times m$ coupling matrices associated with both sets of degrees of freedom, and $\mathbf{P}_{b}(\mathbf{t})$ is the $m$-vector of the reacting forces at the support degrees of freedom.

The equation defining the response degrees of freedom " $a$ " is given by

$$
\mathbf{M}_{a a} \ddot{\mathbf{x}}_{a}+\mathbf{C}_{a a} \dot{\mathbf{x}}_{a}+\mathbf{K}_{a a} \mathbf{x}_{a}=-\mathbf{M}_{a b} \ddot{\mathbf{x}}_{b}-\mathbf{C}_{a b} \dot{\mathbf{x}}_{b}-\mathbf{K}_{a b} \mathbf{x}_{b} .
$$

The solution of (3) depends on how the earthquake motion is defined in the right-hand side of the equation. Equation (3) is the equation of motion for the absolute displacement. Assuming that the mass matrix is diagonal and $\mathbf{C}_{a b}$ is neglected, (3) can be expressed as

$$
\mathbf{M}_{a a} \ddot{\mathbf{x}}_{a}+\mathbf{C}_{a a} \dot{\mathbf{x}}_{a}+\mathbf{K}_{a a} \mathbf{x}_{a}=\mathbf{K}_{a b} \mathbf{x}_{b} .
$$

Equation (4) can be extended to three components:

$$
\mathbf{M}_{a a} \ddot{\mathbf{u}}_{a}+\mathbf{C}_{a a} \dot{\mathbf{u}}_{a}+\mathbf{K}_{a a} \mathbf{u}_{a}=\mathbf{K}_{a b}\left(\mathbf{x}_{b}+\mathbf{y}_{b}+\mathbf{z}_{b}\right),
$$

where $\mathbf{x}_{b}, \mathbf{y}_{b}$, and $\mathbf{z}_{b}$ are the input ground motion displacements in two horizontal directions and one vertical direction, respectively.

\section{The Comparison of Frequencies of Different Systems}

Based on finite element model of transmission tower-line system shown in Figures 2 and 3, the frequencies of the suspension type and tension type system are calculated using dynamic characteristic analysis, respectively. The primary modal frequencies of the transmission tower and line can be obtained, respectively [24].

4.1. The Comparison of Frequencies of the Suspension Type Model. The comparison of the fundamental frequencies of the suspension type model is shown in Table 3 . In the longitudinal direction, the fundamental frequencies of the transmission line and tower of Model 2 are smaller than those of Model 1, but the differences could be ignored. In the transverse direction, the differences between the fundamental frequencies of the transmission line and tower of Model 1 and Model 2 are very small, and the maximum difference is only $1.15 \%$, so the differences cannot be considered. 
TABLE 3: Comparison of the fundamental frequencies of the suspension type model.

\begin{tabular}{lccc}
\hline Frequency & \multicolumn{3}{c}{ Transmission line } \\
& Model 1 $(\mathrm{Hz})$ & Model 2 $(\mathrm{Hz})$ & Difference/\% \\
\hline Longitudinal & 0.1510 & 0.1464 & 3.05 \\
Transverse & 0.1394 & 0.1387 & 1.15 \\
\hline \multirow{2}{*}{ Frequency } & Model 1 (Hz) & Model 2 $(\mathrm{Hz})$ & Difference/\% \\
\hline Longitudinal & 1.7830 & 1.7705 & 0.70 \\
Transverse & 1.7556 & 1.7332 & 1.05 \\
\hline
\end{tabular}

TABLE 4: Comparison of the fundamental frequencies of the tension type model.

\begin{tabular}{lccc}
\hline Frequency & \multicolumn{3}{c}{ Transmission line } \\
& Model 3 (Hz) & Model 4 (Hz) & Difference/\% \\
\hline Longitudinal & 0.2835 & 0.2624 & 7.44 \\
Transverse & 0.1492 & 0.1594 & -6.84 \\
\hline \multirow{2}{*}{ Frequency } & Model 3(Hz) & Transmission tower \\
& 1.4438 & 1.7098 & -18.42 \\
Longitudinal & 1.6707 & 1.6748 & -0.25 \\
Transverse & & & \\
\hline
\end{tabular}

4.2. The Comparison of Frequencies of the Tension Type Model. The comparison of the fundamental frequencies of the tension type model is shown in Table 4 . In the longitudinal direction, the fundamental frequency of the transmission tower of Model 4 is larger than that of Model 3, and the increase of the frequency is $18.4 \%$. However, the fundamental frequency of the transmission line of Model 4 is smaller than that of Model 3, and the decrease of the frequency is 7.4\%. In the transverse direction, the differences between the fundamental frequencies of the transmission tower of Model 4 and Model 3 are small. The fundamental frequency of the transmission line of Model 4 is larger than that of Model 3, and the increase of the frequency is $6.8 \%$.

The variations of the fundamental frequencies of the transmission tower and transmission line of the suspension type and tension type can be obtained based on the above analysis. For the suspension type, the differences between the fundamental frequencies of the transmission tower and line of the two models are very small, and the differences could be ignored. For the tension type, the differences between the fundamental frequencies of the transmission tower of the two models are obvious in the longitudinal direction, but the differences are small in the transverse direction. Therefore, in order to obtain accurate frequencies of the system, Model 1 or Model 2 could be adopted for the suspension type, but Model 4 should be used for the tension type.

\section{Numerical Analysis and Discussion}

The analyses of the suspension type and tension type shown in Figures 2 and 3 under multicomponent and multisupport seismic excitations are calculated using nonlinear time history analysis method, respectively. The damping ratio of

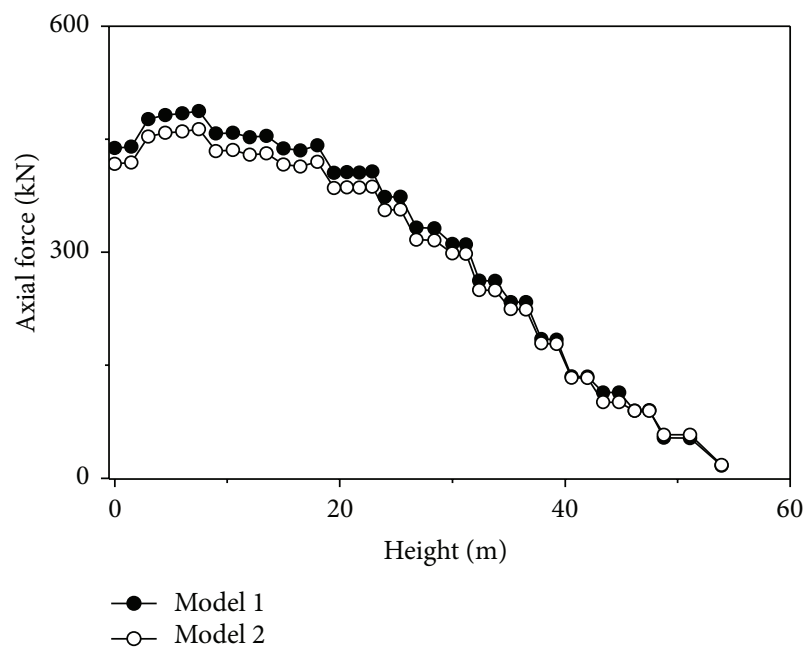

FIGURE 5: Comparison of the maximum axial forces of the transmission towers of the two models of the suspension type.

tower and line is assumed to be $2 \%$ and $1 \%$, respectively. The step-by-step integration of the Hilber-Hughes-Taylor method is used in the dynamic analysis. The longitudinal, transverse, and vertical responses of the two models of the suspension type and tension type are compared, respectively. A reasonable model could be obtained according to the comparison of the responses of the transmission tower and line under nonuniform seismic excitations.

5.1. The Comparison of the Responses of the Suspension Type. The comparison of the maximum axial forces of the transmission towers of the two models of the suspension type under nonuniform seismic excitations is shown in Figure 5. It can be seen from Figure 5 that the axial forces of the transmission tower of Model 1 are larger than those of Model 2 , but the maximum increment is only $5 \%$.

The comparisons of the displacement time histories on the top of the transmission towers of the two models of the suspension type under nonuniform seismic excitations are shown in Figure 6. It can be seen from Figure 6 that the longitudinal and transverse displacements of the transmission tower of Model 1 are larger than those of Model 2, but the differences between the displacement responses of two models are very little, and the shapes of time history curves of the two models are approximately consistent.

From the above analysis, the differences between the responses of the transmission towers of Model 1 and Model 2 of the suspension type under nonuniform seismic excitations are small, and the maximum difference is only $5 \%$. Therefore, Model 1 or Model 2 could give satisfactory results.

The comparisons of the maximum displacements of the transmission lines of the two models of the suspension type are shown in Figure 7. It can be seen from Figure 7 that the differences of the transverse displacements of the transmission lines of the two models are small, and the displacement change slightly with the span varying. The vertical displacements of the transmission line of Model 1 


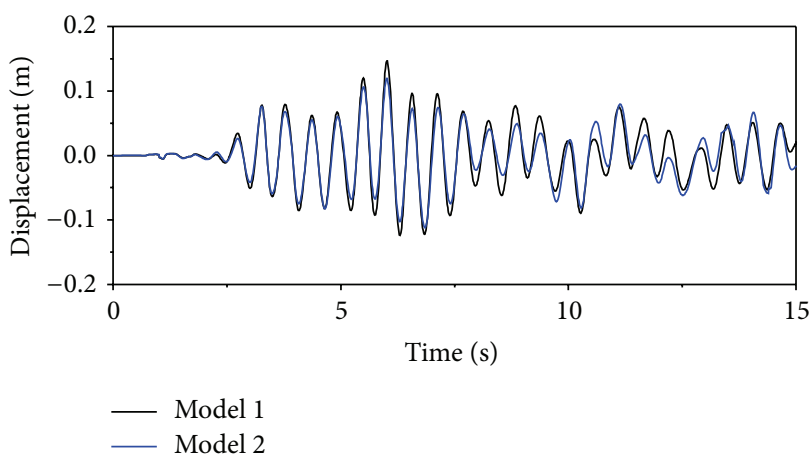

(a) Longitudinal direction

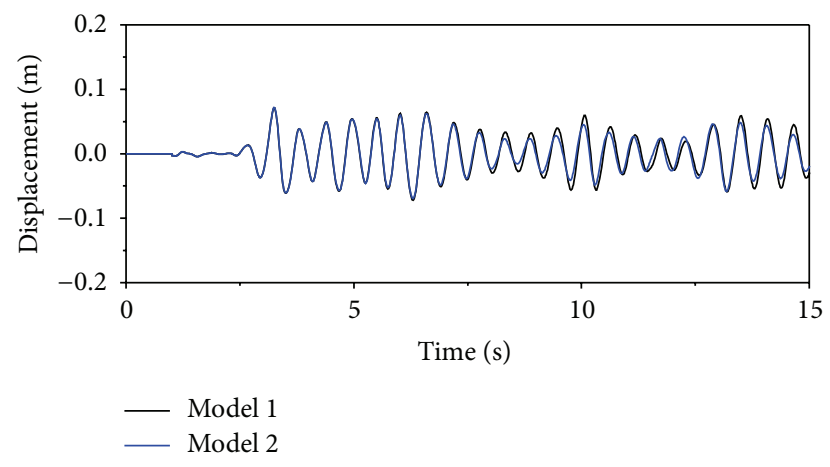

(b) Transverse direction

Figure 6: Comparison of the displacement time histories on the top of the transmission towers of the two models of the suspension type.

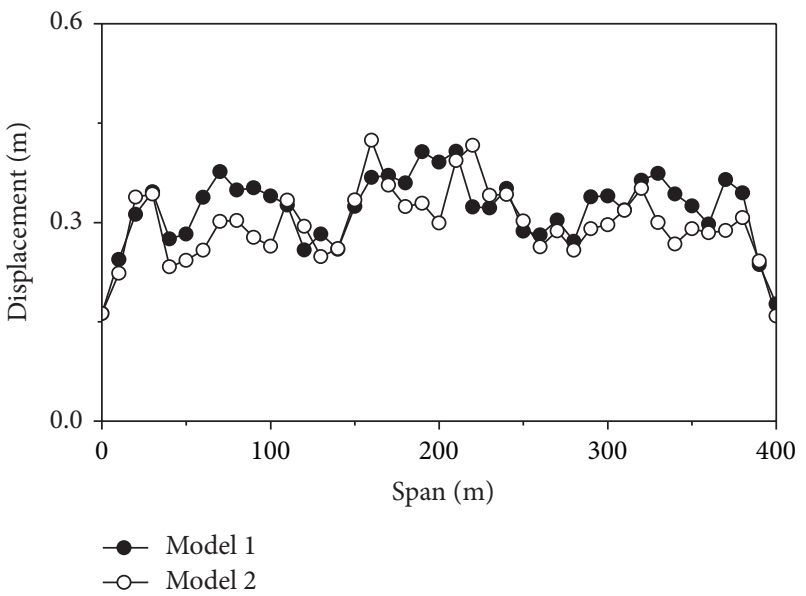

(a) Transverse displacement

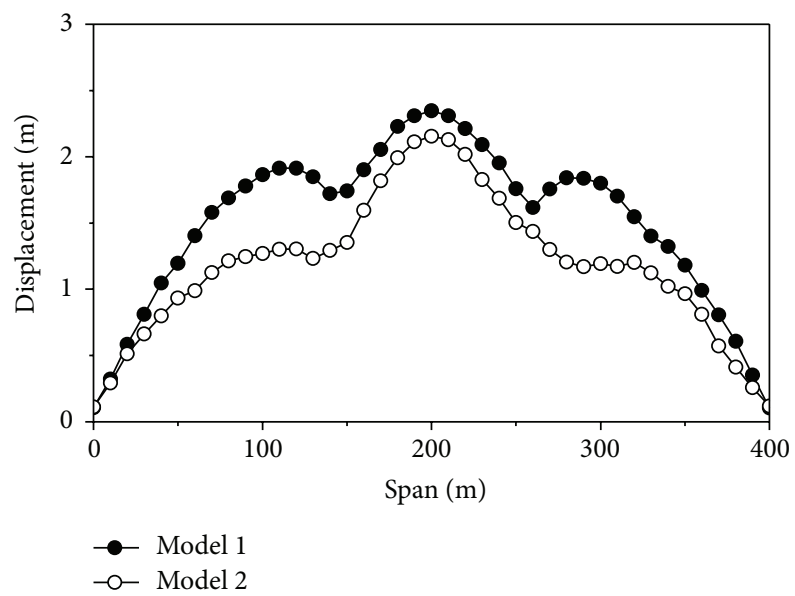

(b) Vertical displacement

FIGURE 7: Comparison of the maximum displacements of the transmission lines of the two models of the suspension type.

are larger than those of Model 2, but the curves of vertical displacements of two models are similar. Because of the suspension type insulator, apparent velocity of seismic wave, and frequencies of the transmission lines, the vertical displacements of the transmission line are symmetrical, and the main reason is the frequency of the transmission lines. The vertical displacement of middle span of the transmission line is the largest in the span due to antisymmetric modes of the transmission lines.

According to the above analysis of Model 1 and Model 2 of the suspension type, Model 1 could meet the requirement because of the effect of two lateral springs. Therefore, Model 1 or Model 2 could be used for calculation model when the system is subjected to nonuniform seismic excitations.

5.2. The Comparison of the Responses of the Tension Type. The comparison of the maximum axial forces of the transmission towers of the two models of the tension type is shown in Figure 8 . It can be seen from Figure 8 that the axial forces of the transmission tower of Model 3 are significantly smaller than those of Model 4, and the maximum decrease is $30 \%$, and the differences of the axial forces between the two models vary obviously at different height of the transmission tower.

Figure 9 shows the comparisons of the displacement time histories on the top of the transmission towers of the two models. It can be seen from Figure 9 that the differences between the longitudinal displacement time histories on the top of the tower of Model 3 and Model 4 are obvious, and the longitudinal displacements on the top of the tower of Model 4 are significantly larger than those of Model 3. Owing to the effect of outside transmission tower, the responses of two models have a phase difference. However, the differences between the transverse displacement time histories on the top of the tower of Model 3 and 4 are small.

According to the results of the transmission tower analysis, the differences between the responses of the transmission towers of Model 3 and Model 4 are significant, especially for the axial forces and longitudinal displacements on the top of the transmission tower. Therefore, in order to obtain accurate responses, Model 4 should be used for seismic analysis of system. Neglecting the effect of the boundary condition, the axial force and the longitudinal maximum displacement of 


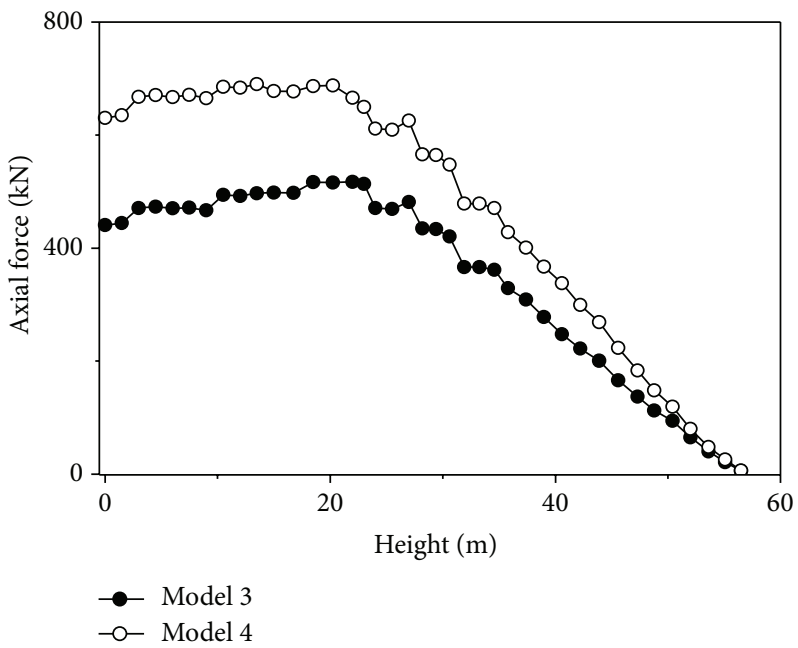

FIgURE 8: Comparison of the maximum axial forces of the transmission towers of the two models of the tension type.

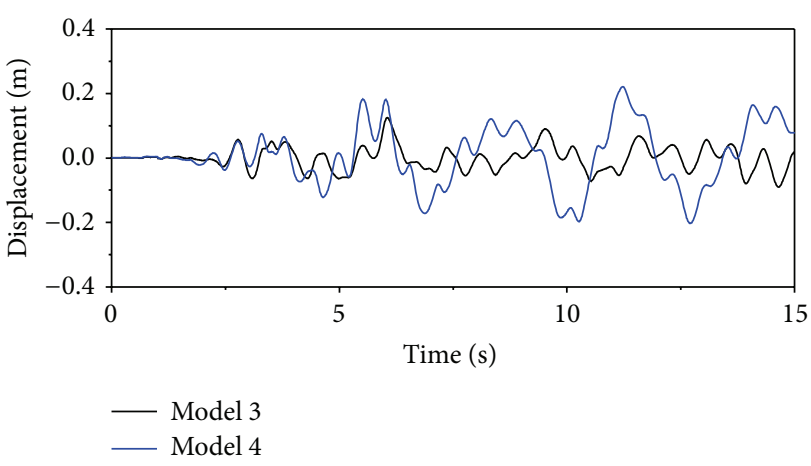

(a) Longitudinal direction

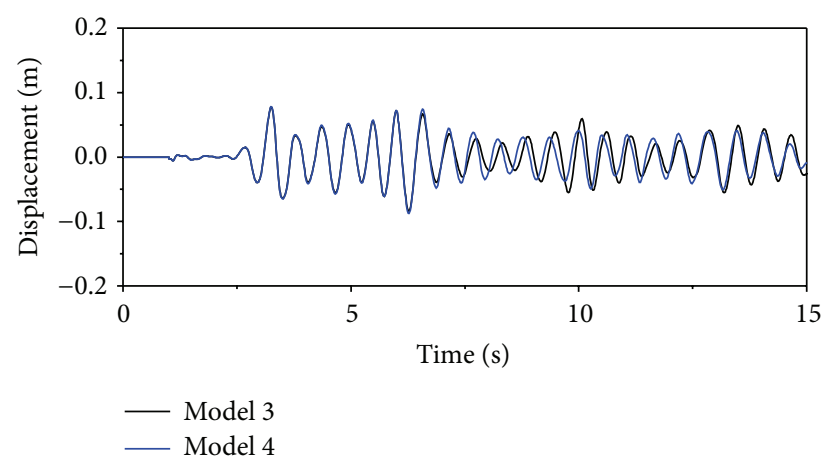

(b) Transverse direction

Figure 9: Comparison of the displacement time histories on the top of the transmission towers of the two models of the tension type.

the transmission tower could be underestimated by more than $30 \%$ and $45 \%$, respectively.

The comparison of the maximum tension forces of the transmission lines of the two models is given in Table 5. It can be seen from Table 5 that the differences between the tension forces of the transmission lines of Model 3 and Model 4 are small, and the maximum difference is only $8 \%$. The tension forces of the transmission line of Model 4 may be larger or smaller than those of Model 3. The effect of the boundary condition could be ignored for the seismic analysis of tension forces of the transmission line.

Figure 10 shows the comparison of the maximum displacements of the transmission lines of the two models of the tension type. It can be seen from Figure 10 that the differences of the transverse displacements of the transmission lines of the two models are small, but the differences of the vertical displacements of the transmission lines of the two models are significant. The maximum vertical displacement of the transmission line of Model 3 is almost two times larger than that of Model 4.

According to the results of the transmission line analysis, the differences between the responses of the transmission lines of Model 3 and Model 4 are obvious, especially for the
TABle 5: Comparison of the maximum tension forces of the transmission lines of the two models of the tension type.

\begin{tabular}{lccc}
\hline Layer & Model 3 $(\mathrm{kN})$ & Model $4(\mathrm{kN})$ & Difference $(\%)$ \\
\hline 1 & 29.73 & 29.46 & 0.92 \\
2 & 81.10 & 88.38 & -8.24 \\
3 & 64.74 & 67.03 & -3.42 \\
4 & 64.15 & 63.08 & 1.70 \\
5 & 45.72 & 43.89 & 4.17 \\
6 & 48.36 & 45.30 & 6.75 \\
7 & 50.40 & 47.46 & 6.19 \\
\hline
\end{tabular}

vertical displacements of the transmission line. Both sides of the transmission tower would tilt easily due to missing the outside transmission line, and the large vertical displacement of transmission line would happen.

The above results demonstrate that the axial forces and longitudinal displacements on the top of the transmission tower of the tension type would be underestimated using Model 3, but the vertical displacements of the transmission line would be seriously overestimated. The seismic responses 


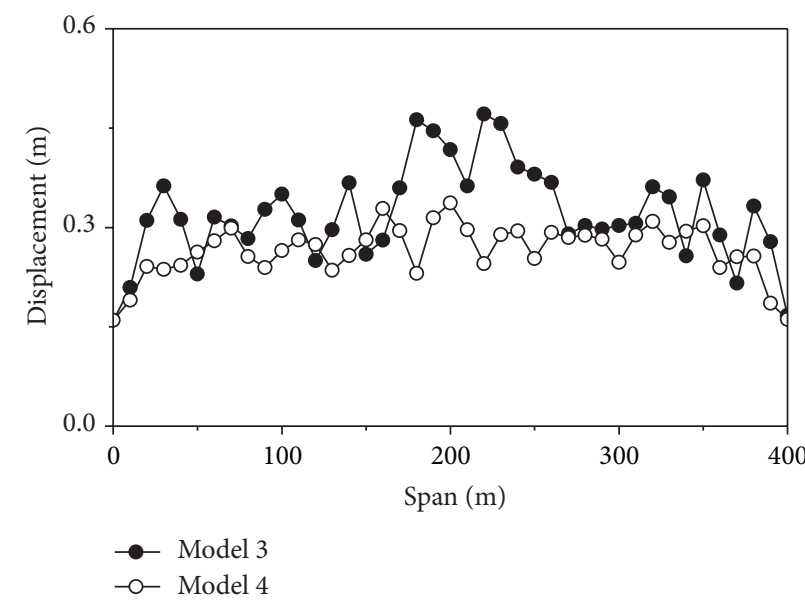

(a) Transverse displacement

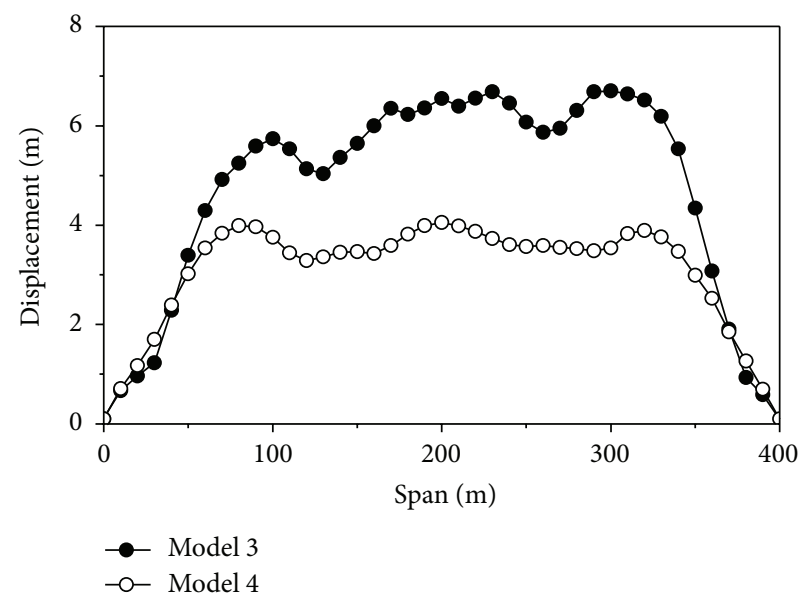

(b) Vertical displacement

FIGURE 10: Comparison of the maximum displacements of the transmission lines of two models of the tension type.

of the transmission tower and the transmission line are not reasonable using Model 3. Therefore, Model 4 should be used for the seismic analysis of the system of the tension type under nonuniform seismic excitations.

\section{Conclusion}

Nonlinear seismic behaviors of different boundary conditions of transmission line systems under nonuniform seismic excitations are studied in this paper. The responses of the suspension type and tension type of the transmission towerline system are investigated using nonlinear time history analysis method, respectively. Based on the numerical results, the following conclusions are drawn:

(1) The frequencies of the two models of the suspension type are slightly different in the longitudinal and transverse directions, but the frequencies of the two models of the tension type are obviously different in the longitudinal direction due to the effect of boundary condition. To obtain an accurate frequency, Model 3 should not be adopted.

(2) The differences between the responses of the transmission tower and transmission line of the two models of the suspension type are very little, so Model 1 can get accurate results and could be used for seismic analysis when the system is under nonuniform seismic excitations.

(3) The responses of the transmission tower and transmission line of the two models of the tension type are significantly different. Neglecting the effect of the boundary condition, the responses of the transmission tower would be underestimated, but the responses of the transmission line would be overestimated. To obtain accurate results, Model 4 should be used for seismic analysis when the system is under nonuniform seismic excitations.
(4) To obtained accurate responses of the system, Model 1 or Model 2 could be used for the seismic analysis of the suspension type transmission tower-line system, but Model 4 should be adopted for the seismic analysis of the tension type transmission tower-line system.

\section{Conflict of Interests}

The authors declare that there is no conflict of interests regarding the publication of this paper.

\section{Acknowledgments}

This research is supported by the National Natural Science Foundation of China under Grant nos. 51208285 and 51578325. The supports for this research are greatly appreciated.

\section{References}

[1] H. Li and H. Bai, "High-voltage transmission tower-line system subjected to disaster loads," Progress in Natural Science: Materials International, vol. 16, no. 9, pp. 899-911, 2006.

[2] M. Shinozuka, "The Hanshin-Awaji earthquake of January 17, 1995 performance of life lines," Tech. Rep. NCEER-95-0015, NCEER, 1995.

[3] C. J. Wong and M. D. Miller, Guidelines for Electrical Transmission Line Structural Loading, American Society of Civil Engineers, New York, NY, USA, 2009.

[4] American Society of Civil Engineers, Design of Latticed Steel Transmission Structures, American Society of Civil Engineers, Reston, Va, USA, 1997.

[5] H. Li and Q. Wang, "Dynamic characteristics of long-span transmission lines and their supporting towers," China Civil Engineering Journal, vol. 30, no. 5, pp. 28-36, 1997.

[6] J. F. Hall, W. T. Holmes, and P. Somers, Northridge Earthquake of January 17, 1994, Earthquake Engineering Research Institute, Oakland, Calif, USA, 1994. 
[7] NCREE, Damage Report on 921 Chi-Chi Earthquake-Lifeline System, NCREE, 1999.

[8] P. Zhang, G. Song, H.-N. Li, and Y.-X. Lin, "Seismic control of power transmission tower using pounding TMD," Journal of Engineering Mechanics, vol. 139, no. 10, pp. 1395-1406, 2013.

[9] J. Eidinger, "Wenchuan earthquake impact to power systems," in Proceedings of the Lifeline Earthquake Engineering in a Multihazard Environment (TCLEE'09), pp. 1-12, Oakland, Calif, USA, June-July 2009.

[10] H. Li, W. Shi, and L. Jia, "Limitations of effects of lines on inplane vibration of transmission towers and simplified seismic calculation method," Journal of Vibration and Shock, vol. 23, no. 2, pp. 1-7, 2004.

[11] H.-N. Li, W.-L. Shi, G.-X. Wang, and L.-G. Jia, "Simplified models and experimental verification for coupled transmission tower-line system to seismic excitations," Journal of Sound and Vibration, vol. 286, no. 3, pp. 569-585, 2005.

[12] T. Suzuki, K. Tamamatsu, and T. Fukasawa, "Seismic response characteristics of transmission towers," in Proceedings of the 10th World Conference on Earthquake Engineering, pp. 4961-4967, Madrid, Spain, July 1992.

[13] A. Ghobarah, T. S. Aziz, and M. El-Attar, "Response of transmission lines to multiple support excitation," Engineering Structures, vol. 18, no. 12, pp. 936-946, 1996.

[14] H. Li, S. Xiao, and S. Wang, "Model of transmission towerpile-soil dynamic interaction under earthquake: in-plane," in Proceedings of the ASME Pressure Vessels and Piping Conference, pp. 143-147, Vancouver, Canada, August 2002.

[15] Y.-H. Lei and Y.-L. Chien, "Seismic analysis of transmission towers considering both geometric and material nonlinearities," Tamkang Journal of Science and Engineering, vol. 8, no. 1, pp. 2942, 2005.

[16] F.-L. Bai, H. Hao, K.-M. Bi, and H.-N. Li, "Seismic response analysis of transmission tower-line system on a heterogeneous site to multi-component spatial ground motions," Advances in Structural Engineering, vol. 14, no. 3, pp. 457-474, 2011.

[17] W. M. Wang, H. N. Li, and L. Tian, "Progressive collapse analysis of transmission tower-line system under earthquake," Advanced Steel Construction, vol. 9, no. 2, pp. 161-174, 2013.

[18] G. Wu, C.-H. Zhai, S. Li, and L.-L. Xie, "Seismic response of large crossing transmission tower-line system subjected to nearfault ground motions," Engineering Mechanics, vol. 30, no. 6, pp. 77-82, 2013.

[19] L. Tian, H. Li, and G. Liu, "Seismic response of power transmission tower-line system subjected to spatially varying ground motions," Mathematical Problems in Engineering, vol. 2010, Article ID 587317, 20 pages, 2010.

[20] H. Deng, X. Chen, H. Tu, X. Ma, and Z. Wang, "Experimental study on model of Jiangyin long span transmission tower," Journal of Building Structures, vol. 22, no. 6, pp. 31-35, 2001.

[21] S. Shen, C. Xu, and C. Zhao, Design of Suspension Structure, China Architecture and Building Press, Beijing, China, 1997.

[22] R. W. Clough and J. Penzien, Dynamics of Structures, McGrawHill, New York, NY, USA, 1975.

[23] E. L. Wilson, Three Dimensional Static and Dynamic Analysis of Structures: A Physical Approach with Emphasis on Earthquake Engineering, Computer and Structures, Berkeley, Calif, USA, 2002.

[24] H. Yasui, H. Marukawa, Y. Momomura, and T. Ohkuma, "Analytical study on wind-induced vibration of power transmission towers," Journal of Wind Engineering and Industrial Aerodynamics, vol. 83, no. 2, pp. 431-441, 1999. 


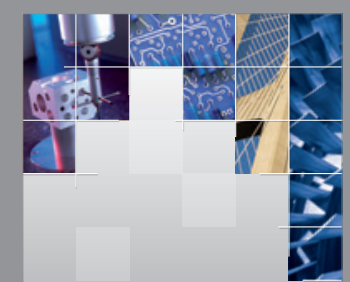

\section{Enfincering}
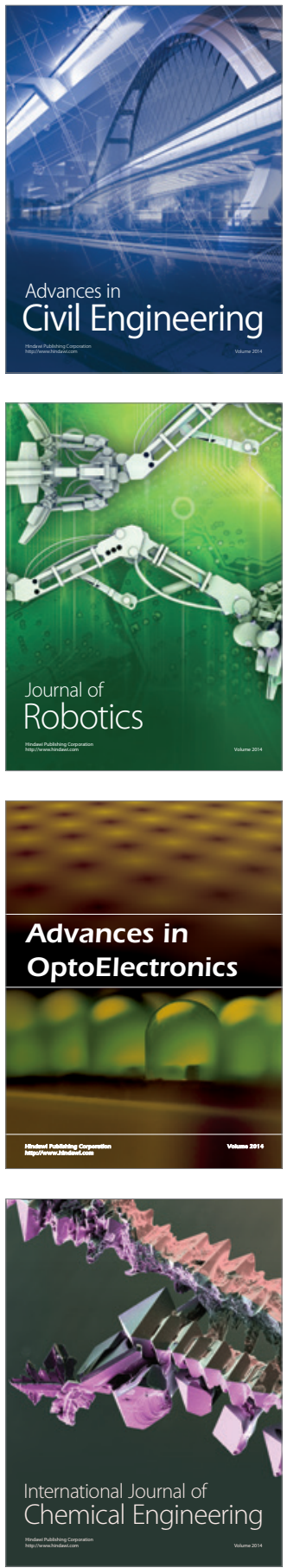

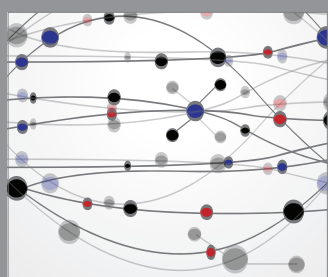

The Scientific World Journal

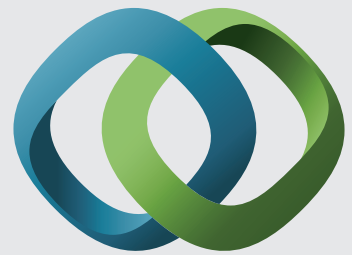

\section{Hindawi}

Submit your manuscripts at

http://www.hindawi.com
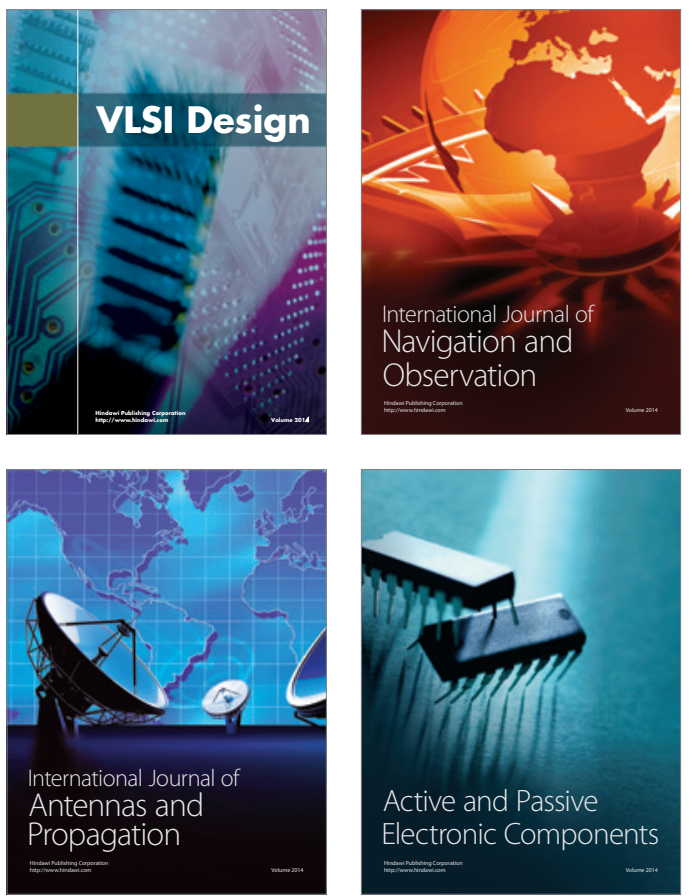
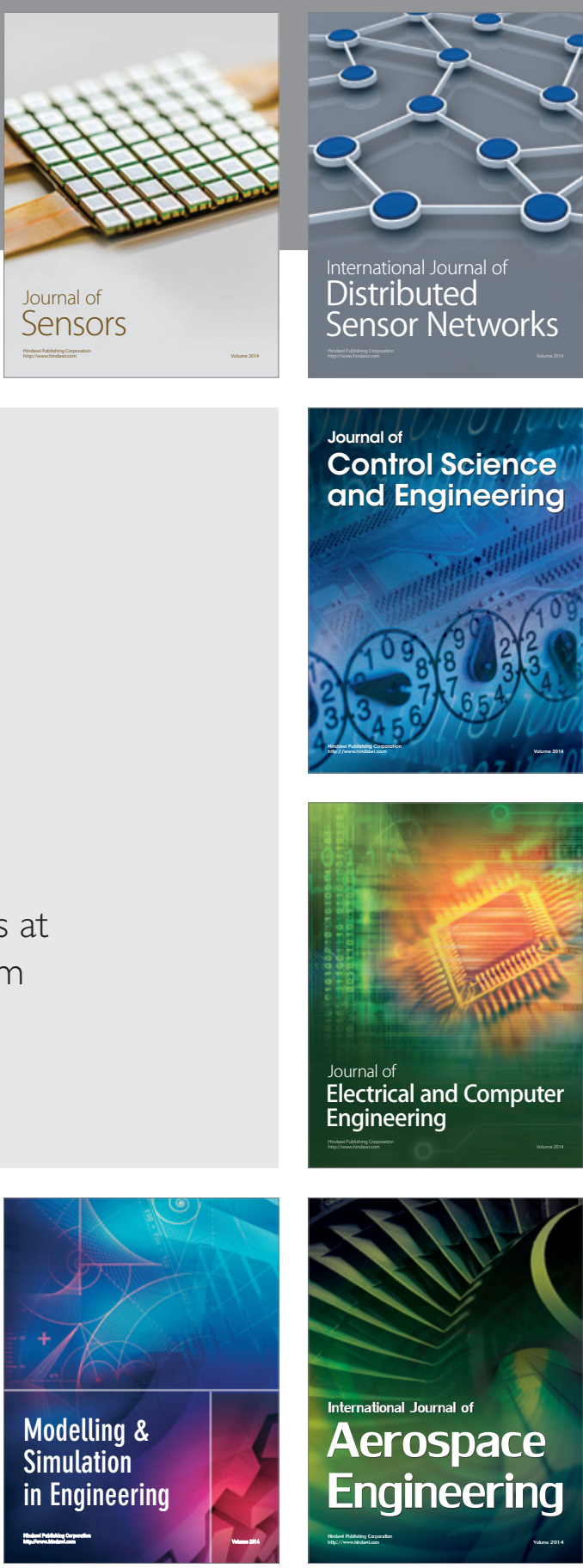

International Journal of

Distributed

Sensor Networks

Journal of

Control Science

and Engineering
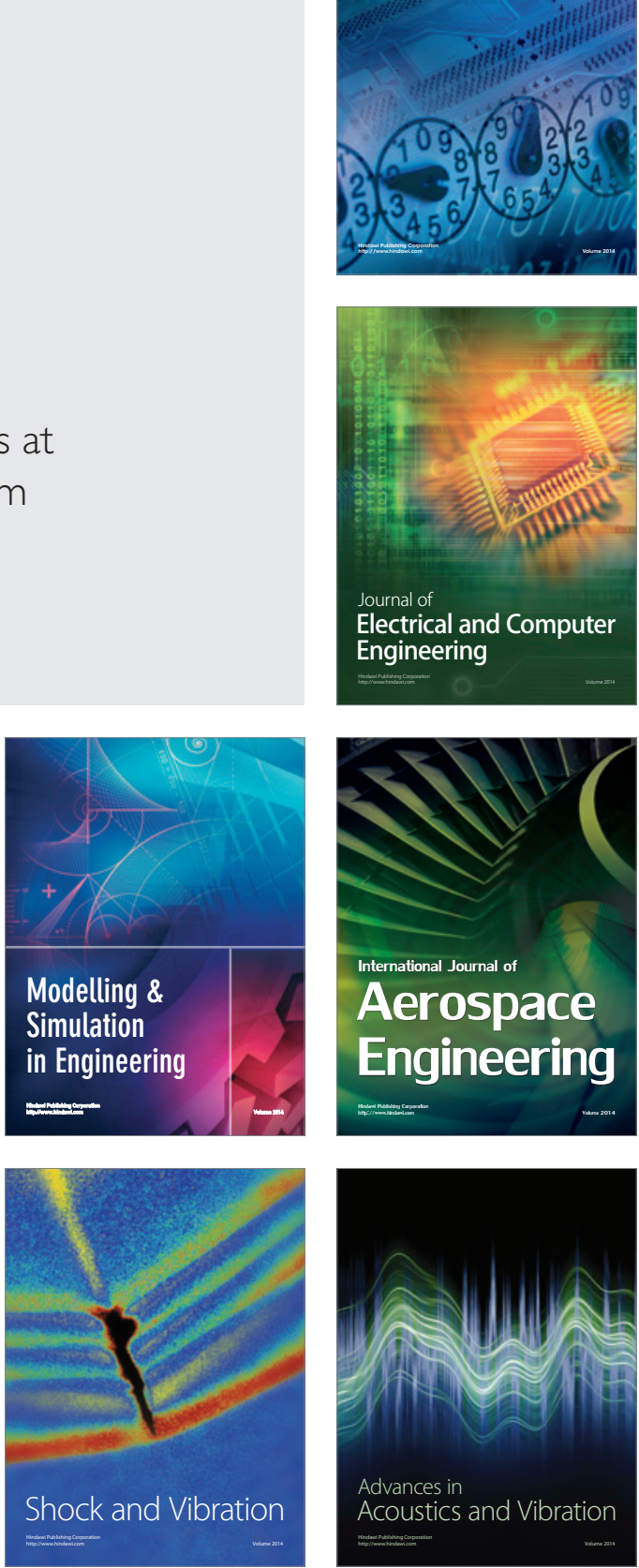